\title{
Bimalleolar Fractures of Ankle -Review of Surgical Management
}

\author{
Dr Sunil V Patil, Prof \& HOD Orthopedics, Dr Rohan Kore . Senior Resident \\ Bharati Vidyapeeth Deemed University Medical College \& Hospital, Sangli \\ Bharati Vidyapeeth Deemed University Medical College \& Hospital, Sangli
}

\begin{abstract}
:
Introduction

Ankle Fractures are common fractures of Lower limb which require surgical intervention. $25 \%$ are usually Bimalleolar fractures .Cast Application has only role in undisplaced crack Fractures. As maintainance of Reduction is a big problem Surgical Fixation of both pillars of ankle has become a Dictum \& Rule of Thumb.

Material \& Methods: In our Institute Prospective \& Retro spective study was carried out on 38 patients from Jan 2010 To Dec 2014.( 28 Males \& 10 females), with a mean age of 44 years.(26 -68 years), who underwent surgical Fixation of Bimalleolar Fractures. Mean Follow-up 24 Months (10 -34 months.)

According To Lange Hansen Classification .the mechanism of occurrence was

1. Supination Ext-Rotation.(SER) 16 cases. (42\%).

2. Pronation Ext-Rotation (PER) 13 cases (36\%)

3. Supination Adduction (SAD) 6 cases $(16 \%)$.

4. Pronation Abduction (PAB) 3 cases (6\%).

There were $5(13.75 \%)$ cases associated with dislocation.Dislocations were reduced as an emergency surgical procedure. 2 cases were associated with Compound Injury which was Gustillo-Anderson Gr 2. All fractures were openly reduced \& fixed by various implants .

The Trauma - Surgery Interval was 2 days (12 hrs to 8 days.)

Results: Average satisfactory results were obtained in all patients(100\%).

The average union time was 9-10 wks (8-14 wks). Malleolar Screws gave good results of Fixation of Med Malleolus (80\%)\& 1/.3 ${ }^{\text {rd }}$ Tubular Plate gave good results for Lat malleolus ( Fibula)87\%. K- wires \& TBW was a good option in osteoporotic Patients. Of the 38 cases acc to Ankle Society Criteria we had 28 good results(74\%) 8 had fair outcome (21\%) 2 had poor results.(5\%) Commonest Complication was Joint Stiffness \& Superficial Infection.
\end{abstract}

Conclusion: Anatomical Reduction especially Fibular length \& early mobilization gave Excellent results. Key Words:- Bimalleolar, Primary Osteo-synthesis, Mortise Congruity.

\section{Introduction}

Ankle Joint is a complex hinge weight bearing joint with bones \& Ligaments playing an important role in the inherant stability. The injuries of the ankle range from minor sprains, Strains to unimalleolar, bi-malleolar tri- malleolar fractures with or with out dislocation $\&$ of plafond fractures. Due to heavy velocity injuries the incidence of such fractures is on rise. Isolated malleolar fractures form $2 / 3{ }^{\text {rd }}$ of total malleolar Fractures. Bimalleolar Fractures form $1 / 4^{\text {th }}$ of the total, \& the rest are all trimalleolar Fractures.

Bimalleolar Fractures cause the loss of Stability by disturbing the pillar structure \& there by reduces th tibio-talar contact area \& alters the joint congruity. Therefore achieving the pillar allignment \& joint congruity is the key to good outcome \& restores stable ankle Function. Initial wokers tried to stabilize by closed reduction \& External plaster but failed because when the oedema subsided, the cast was loose \& the reduction gave way producing very poor results. Also prolonged immobilization caused huge problem of Fracture disease, especially in geriatric age group.It also Increased the incidence of post traumatic arthritis So open reduction \& Internal Fixation became the dictom. The primary goal of uncompromised return could only be achieved by fixation in anatomical reduction \& maintenance of both pillars, giving a normal, stable ankle joint.

\section{Material \& Methods}

A prospective study was done in 38 cases over a period from Jan10 to Dec 14 in Bharati Vidyapeeth University Medical College \& Hospital Sangli.. All were bimalleolar fractures were with out Dislocation. There were 28 males $\& 10$ females .Mean age was 44 years $(26-68$ years $) .3$ cases were in the $6^{\text {th }}$ decade, \& 8 were in the $5^{\text {th }}$ decade, Right sided fractures were $20 \&$ Left sided were 18 . Most of the injuries were due to Road Traffic Accident-26 patients, Domestic Injury in 12 patients of which 8 were more than 50 years of age. 
According To Lange Hansen Classification .The mechanism of occurrence in our Series was as Follows:-

\begin{tabular}{|c|c|}
\hline Supination Ext- Rotation.( & 16 cases. \\
\hline Ext Rotation & 13 cases. \\
\hline Supination Adduction (SAI & cases. \\
\hline Pronation Abduction (PAB) & 03 cases. \\
\hline
\end{tabular}

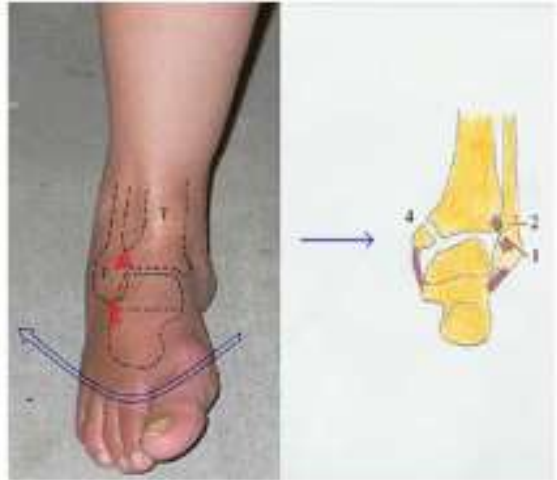

Supination Ext Rotation $16 / 38(42 \%)$

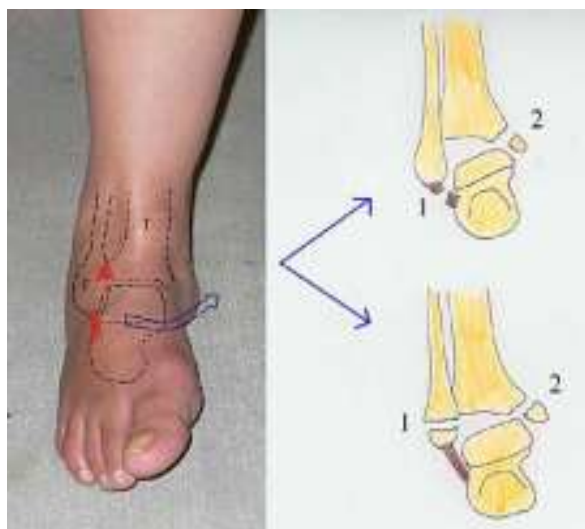

Supination Adduction 6/38 (16\%)

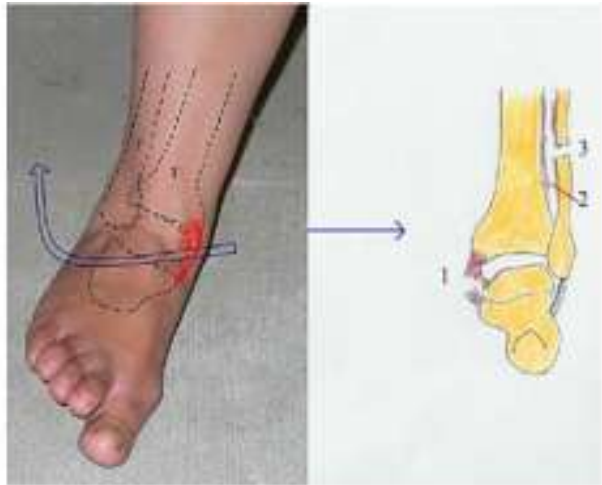

Pronation Ext Rotation 13/38 (36\%)

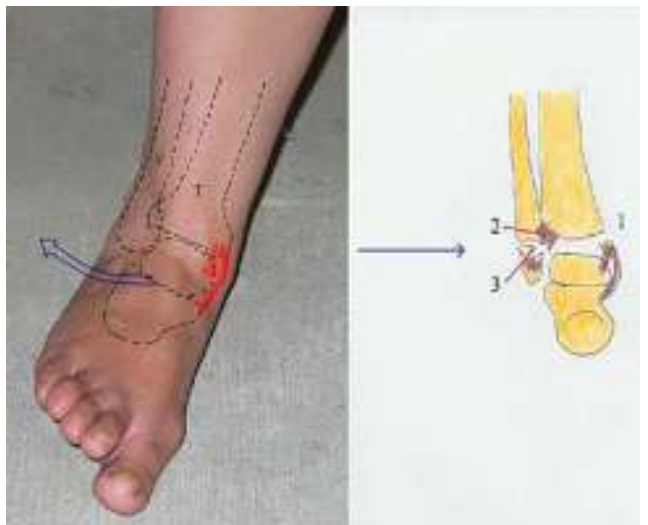

Pronation Abduction: 3/38 (06\%)

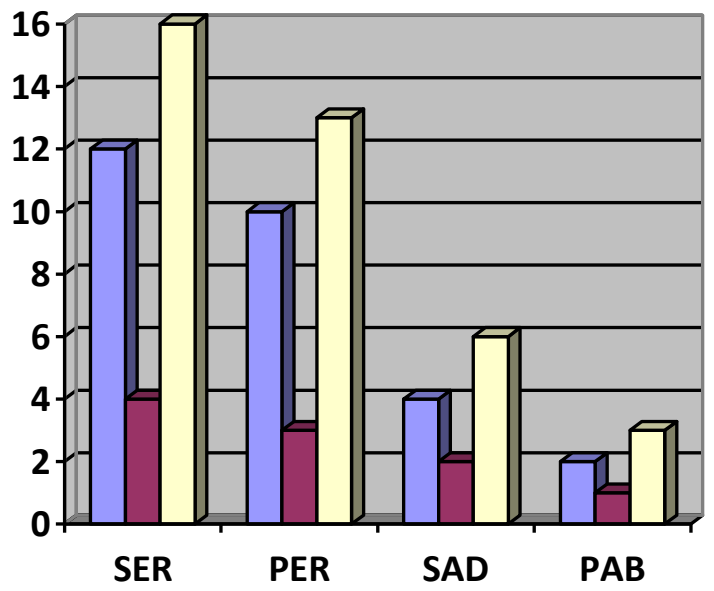

$\square$ Male
$\square$ Female
$\square$ Total

All were classified as Unstable Fractures needing Surgery.

There were $5(13.75 \%)$ cases associated with dislocation. Dislocation were reduced as an emergency surgical procedure . 2 cases were associated with Compound Injury which was Gustillo - Anderson Gr 2. All fractures were openly reduced \& fixed by various implants .

The Average Trauma - Surgery Interval was 4 days (12 hrs to 8 days.)

Associated Injuries to Proximal Tibia........2 cases.

Shaft Tibia ........ 3 cases 
Supracondylar Femur ... 2 cases.

Bimalleolar Fractures were fixed along with the Other Fracture preferably in 1 sitting only. Compound Fractures were treated on separate days.

Preoperatively the limb was elevated .ICE packs were given \& crepe bandage was applied with a Temporary Posterior Plaster Splint

All fractures had undergone Open Reduction \& Fixation of Medial Malleolus by

1.Malleolar Screw $4 \mathrm{~mm}$

2 Malleolar Screw with K-wire \& TBW.

The Lateral malleolus was Fixed by means of

$1.1 / 3^{\text {rd }}$ Tubular Plate

2.3.5mm Dynamic Compression Plate

3.3.5 mm Reconstruction plate./ Anti glide plate.

4. $3.5 \mathrm{~mm}$ cortical inter-frag lag screw.

Syndesmotic screw was fixed in 5 cases by means of $3.5 \mathrm{~mm}$ cortical screw after judging the stability intra operatively by Colton'; s Test.

All surgeries were done under IITV \& Tourniquet \& preferably Spinal or Epidural Anaesthesia. The Average Op Time was $1 \mathrm{hr}$.

Operative Procedure:-

For Lateral Malleolus - the fibula was Fixed first as a routine procedure which exposed from lateral approach, anatomically reduced by Bone \& Plate holding clamps \& fixed with $1 / 3^{\text {rd }}$ Tubular plates -20 cases(14-SER, 4-PER, 1-PA \& 1 SA.)

$3.5 \mathrm{~mm}$ DCP was used in 10 cases. (5-PER, 2-SER, 1-PA, 2 -SA).

Reconstruction Plate was used in 6 cases.(SER-2, PER-2, PA-1, SA-1).

L-wire used in 2 cases.(PER-1 \& PA-1).

For Medial Malleolus:-A antero-medial approach was taken, fracture site exposed \& edges freshened \& anatomically reduced \& Fixed with malleolar screw $4 \mathrm{~mm}$ in 18 cases(7-SER, 8- PER, 2- PA, 1-SA). In 2 cases Deltoid lig which was also injured was diagnosed \& treated accordingly.

After fixation the stability was checked \& Syndesmotic Screw was fixed in 5 cases (PER-4, SER-1).with $3.5 \mathrm{~mm}$ cortical screw with three cortical purchase as per AO principles.

Lateral malleolus was always fixed initially. then the Syndesmotic screw was fixed $1 \mathrm{~cm}$ from joint line if necessary.(Colton's Test $+v e$ ) Then the medial malleolus.

In Gr II compound wound initial Primary debridement was done with Betadine \& Hydrogen Peroxide on the same day. A posterior splint \& I/V Antibiotics was given for 5 days.

All compound fractures were of PER type, \& had a wound on the Medial side.They were fixed after 5-6 days after skin condition became favourable.

\section{Post-operative:-}

$\mathrm{I} / \mathrm{v}$ antibiotics was given for 5 a period of days, the limb was elevated \& supported by a posterior splint. Toe movements were encouraged the same day. Knee Flexion was started from day1, \& non- weight bearing was allowed on Crutches from day 3 depending upon tolerance of the patient. Sutures were removed on the $12^{\text {th }}$ day \& a Below knee plaster was given. Patient was advised non wt bearing physiotherapy for atleast 6-8 weeks till follow-up Xrays taken every month showed signs of healing \& Clinical Examination reveals pain free movement at ankle.

\section{Results}

Results were evaluated by means of Ankle Society (R-B Criteria)It is Subjective \& Objective clinical criteria with Radiographic results based on presence of pain, stability, Range of movements, $\&$ ability to walk $\&$ run. Ankle Society Score has max score 100.points.

Clinical evaluation has 75 points. Radiolgical evaluation has .max 25 points.

Accordingly more than 90 means Excellent to Good .

Less than 80 means poor results.

Satisfactory union were seen in all cases.(100\%)

Average union time was obtained in 10 wks.(8 -16 weeks).Excellant Results in

26 cases . $(74 \%)$ Fair in 9 cases $(20 \%)$, poor in 3 cases $(6 \%)$. 


\begin{tabular}{|l|l|l|l|l|l|}
\hline Serial No & Type Of \# Mechanism n=38 & Excellant & Good & Fair & Poor \\
\hline 1 & SER 16/38=42\% & $10(62.5 \%)$ & $03(18.75 \%)$ & $02(12.5 \%)$ & $01(6.25 \%)$ \\
\hline 2 & PER 13/38=36\% & $06(46.15 \%)$ & $03(23.08 \%)$ & $03(23.07 \%)$ & $01(7.70 \%)$ \\
\hline 3 & SAD 06/38=16\% & $02(33.33 \%)$ & $02(33.33 \%)$ & $01(16.67 \%)$ & $01(16.67 \%)$ \\
\hline 4 & PAB03/38=06\% & $0133.33 \%)$ & $01(33.33 \%)$ & $01(33.33 \%)$ & $0(0 \%)$. \\
\hline
\end{tabular}

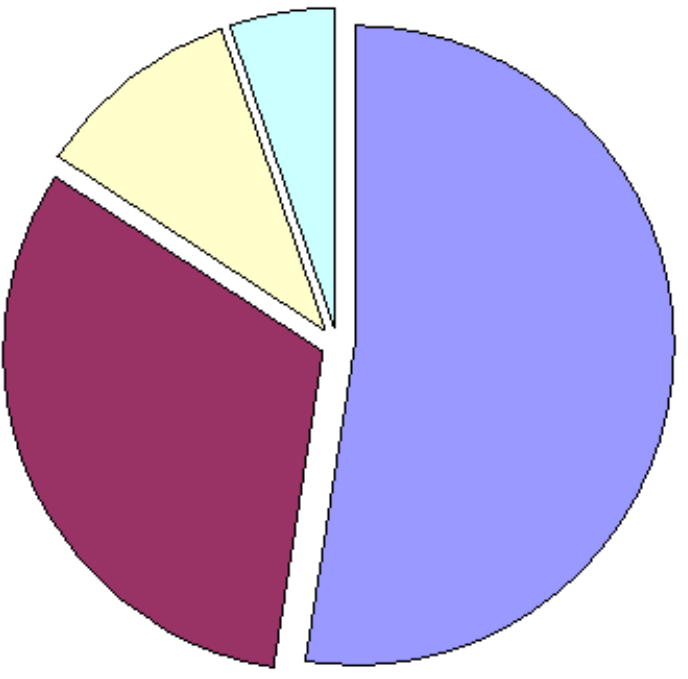

$\square$ Excellent
$\square$ Good
$\square$ Fair
$\square$ Poor

\section{Complication}

1. Superficial Infections 6/38...(16\%)

2. Implant Failure $\quad 4 / 38 \ldots . . .(10.5 \%)$
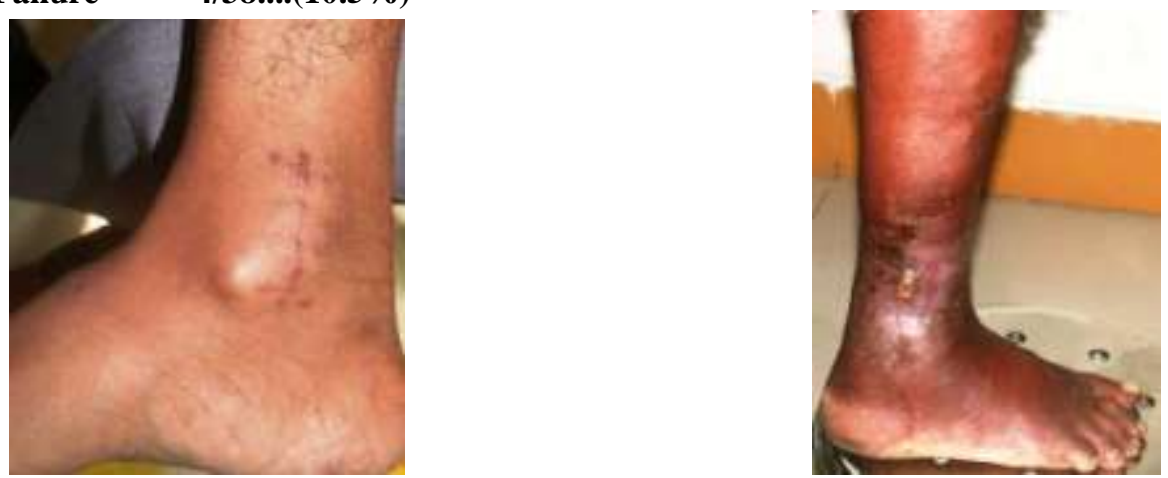

Cases \& Observations;-
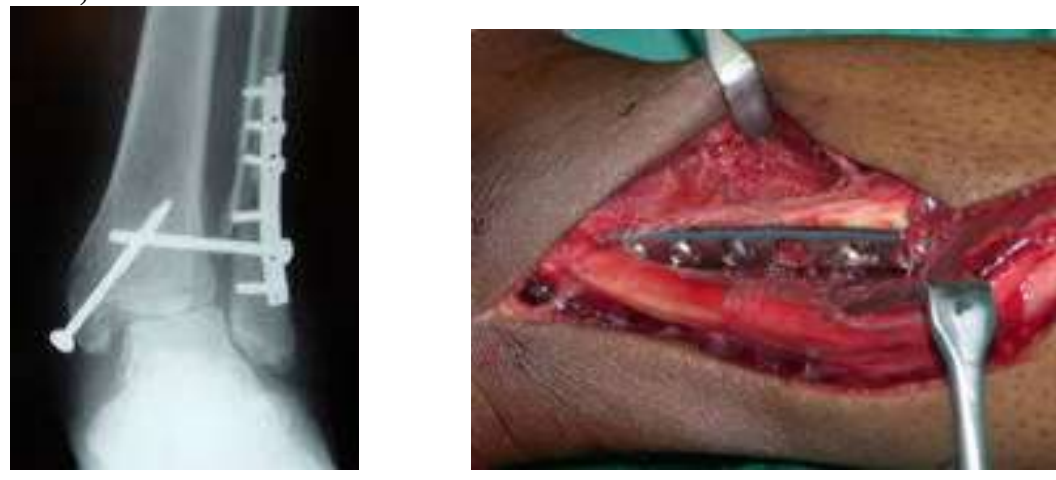

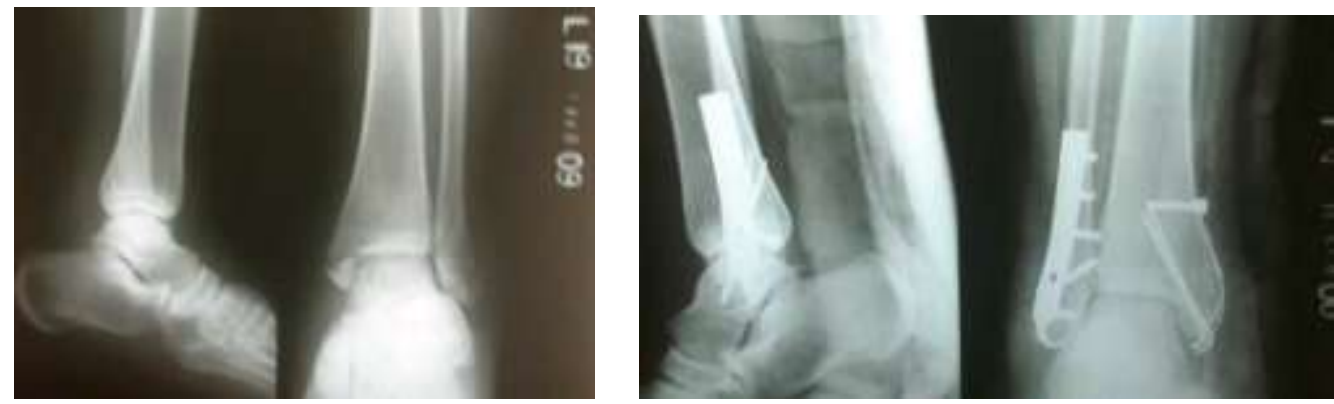

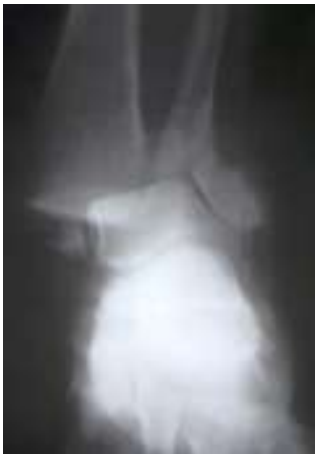

A

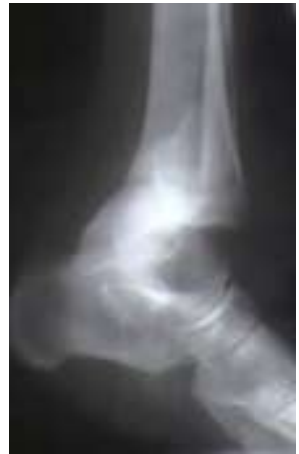

B
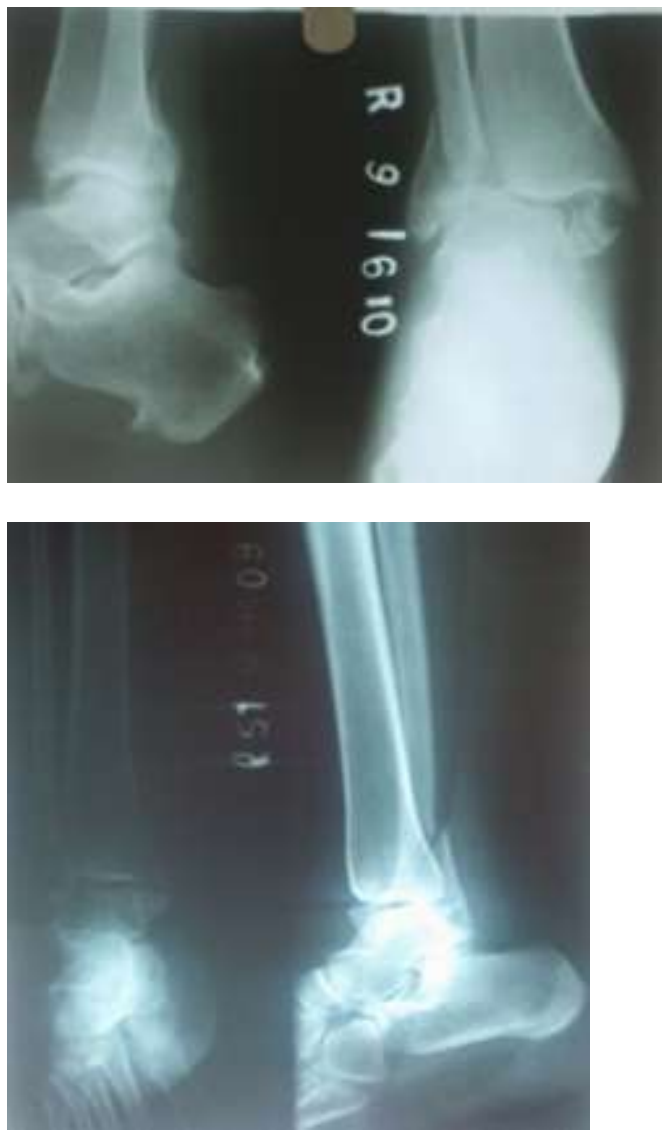

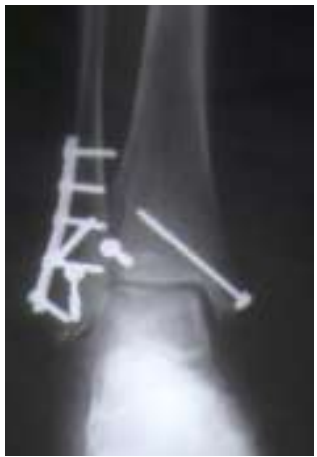

$\mathrm{C}$

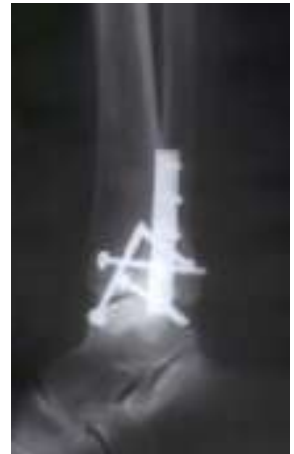

$\mathrm{D}$
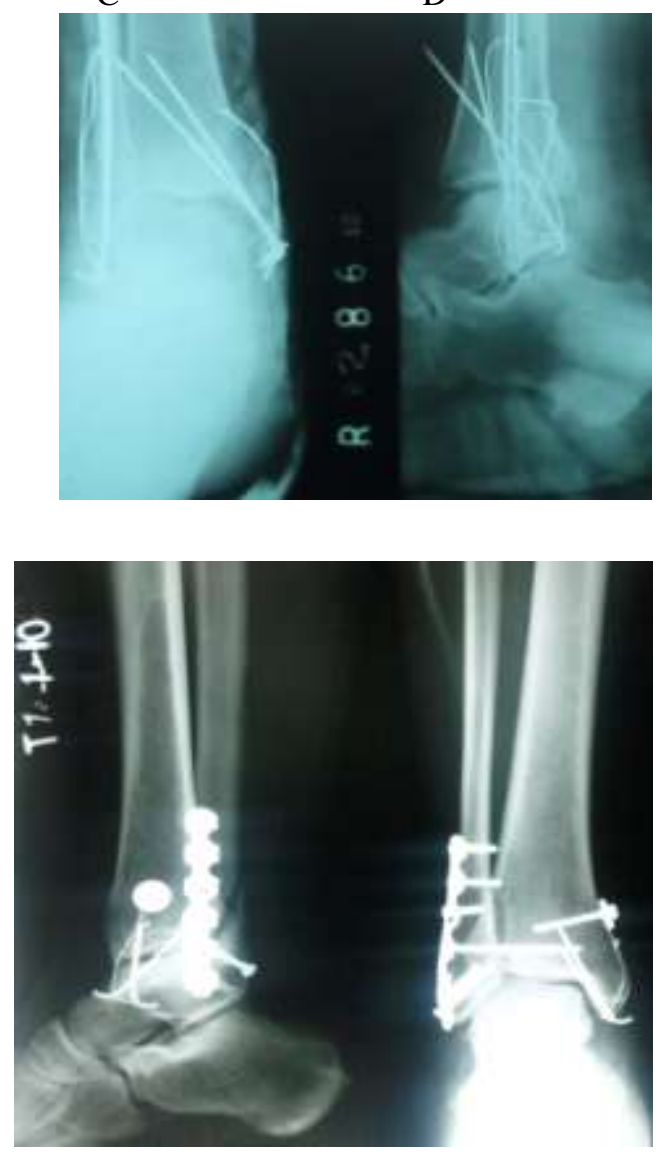

\section{Discussion}

The fractures of the ankle are injuries seen in the young and middle aged patients commonly. The mean age in our series was noted to be 36 yrs with a male predominance of $73.68 \%$ 
Table 9:- Sex distribution in various studies

\begin{tabular}{|l|l|l|l|l|}
\hline Study & No Of Patients & Males & Females & $\%$ Of Males \\
\hline Robert SR & 25 & 11 & 14 & $44 \%$ \\
\hline Berris et al & 144 & 56 & 88 & $38.8 \%$ \\
\hline Present Study & 38 & 28 & 10 & $73.68 \%$ \\
\hline
\end{tabular}

Sex distribution in our study showed a male preponderance compared to other studies.

Weber's Type B fractures consisted of $53.7 \%$

\begin{tabular}{|l|l|l|l|l|}
\hline Sr No & Study & No Of Patients & Weber Type \# & Percentage \\
\hline 1 & Liestal & 108 & TypeB & $64.8 \%$ \\
\hline 2 & Freibrug & 100 & Type B & $60 \%$ \\
\hline 3 & St Gallen & 130 & Type C & $47.7 \%$ \\
\hline 4 & Present Study & 38 & Type B & $63 \%$ \\
\hline
\end{tabular}

Table 11:- Weber's type of injury:

The findings were similar to those of Leistal and Freibrug.

The present study suggests anatomical reduction of the fracture and restoration of the joint congruity of the ankle at the earliest.

The post operative immobilization in a plaster slab or a cast upto six weeks does not affect the final outcome with respect to achieveing the ankle and subtalar range of movements as most of the patients had achieved full range of motion at the end of 12 weeks.

The factors that affected the final poor outcome were the presence of long standing and uncontrolled Diabetes and old age, which was seen in four cases of which one had a neuropathic foot. the talus as drawn across the medial and lateral talar ridges and a difference of $2 \mathrm{~mm}$ is abnormal. This is also measured by the differences in the perpendicular line across the top of the talus and the weight bearing line down the centre of the tibia on the anteroposterior film and a difference of more than 50 from the contralateral side is abnormal. Syndesmotic width is the horizontal distance from the tibial incisura to the medial border of fibula.

\section{Conclusion}

1) The fractures of the ankle are commonly seen in the young adult male population with Road traffic accidents and twisting injuries being the common causes.

2) Right side ankles were commonly involved than the left side.

3) Weber type B was the commonest type of fracture. Supination external rotation injury was the most common mechanism of injury.

4) The aim of surgery is to achieve anatomical reduction of the fracture fragments, ankle mortise congruity, restoration of the length of the fibula and restoration of syndesmotic integrity.

5) During surgery, the soft tissues dissection was kept minimal to avoid further vascular compromise in an already tense, swollen ankle.

6) In the post operative period, splintage of the ankle and precaution to prevent swelling of the ankle is necessary. The swelling may lead to delayed wound healing. Patients are ambulated with crutches or walker without bearing weight on the injured limb from the first post operative day if there are no associated injuries and can be discharged from the hospital by the first week.

7) Most of the fractures in our study were fixed within 24 hours which however did not change the final outcome, though other studies have stressed upon fixation within 8 hours of injury. The complications that arose were in those where the fractures were fixed after 24 hours which were delayed wound healing and superficial infections of the wound which mostly healed with regular wound care.

8) The six week period of immobilization did not affect the final range of ankle function as most patients had achieved full range of motion by the end of 12 weeks postoperatively with active exercise regimen.

9) The result of this study in comparison with other studies as enumerated shows similar findings with respect to the functional outcome following surgical stabilization of bimalleolar fractures. The rarity of complications in comparison to other studies may be due to a small number of patients and a very short period of follow up.

10) Our study used Lauge Hansen's classification for mechanism of injury and Weber's classification for radiological classification. We recommend use of Weber's Classification for management which is easier for classification and radiological assessment. 


\section{References}

[1]. Alexander Beris et al. surgical treatment of malleolar fractures. CORR, 1997, No 341,p 90

[2]. Alfons F.C.C de Kort, Distal tibio fibular synostosis after ankle fracture, 1996 JBJS.

[3]. Ashurst-Bromer-Rockwood and greens fractures in adult, fourth edition 1996,s p 2201

[4]. Astley Cooper-Rockwood and greens fracture in adults, fourth edition 1996, p 2201.

[5]. Baron Dupuytren - Rockwood and Greens fractures in adults, fourth edition 1996, p 2201.

[6]. Beauchamp.C.G. et al Displaced ankle fractures in patients over 50 yrs of age. JBJS 1983 65B.p 329.

[7]. Benedikt Winkler. Et al. The dorsal antiglide plate in the treatment of Danis Weber type B fractures of the distal fibula. CORR 1990, No 259, p 204

[8]. Bonnet-Rockwood and Greens fractures in adults, fourth edition 1996, p 2201.

[9]. Bostman. O et al Ankle fractures treated using biodegradable internal fixation. CORR 1989, no 238, p 195.

[10]. Boyer-Rockwood and Greens fractures in adults, fourth edition 1996, p 2201.

[11]. C Niek van Dijk. Distal tibiofibular synostosis after ankle fracture. 1996 JBJS. Vol 78B, p 250.

[12]. Cassandra Lee BS. Over tightening of the ankle syndesmosis, Is it really possible. JBJS 2001 VOL 83A, no 4, p 489.

[13]. Chaput. Rockwood and Greens fractures in adults, fourth edition 1996, p 2201

[14]. Christopher Bibbo, DO, complications of ankle fractures in diabetic patients. OCNA JAN 2001 VOL 32, no 1, p 113.

[15]. Cotton-Rockwood and Greens fractures in adults, fourth edition 1996, p 2201.

[16]. D I Rowley, A prospective trial comparing operative and manipulative treatment of ankle fractures JBJS 1986 VOL 68 B p 610 .

[17]. D.M. Forrester, MD. Magnetic resonance imaging of the foot and ankle trauma. OCNa 1990, vol 21, no 3, p 591.

[18]. Danis. Rockwood and Greens fractures in adults, fourth edition 1996, p 2201.

[19]. David. J. Musgrave MD, Intraoperative radiographic assessment of ankle fractures. CORR 1998 No 351 , p 186.

[20]. David Segal MD, Functional bracing and rehabilitation of ankle fractures. CORR 1985 No 199, p 39.

[21]. Dolf Ichtertz MD, Early mobilization of the ankle fractures after open reduction and internal fixation. CORR. 1991 no 267, p 152

[22]. Donald A Wiss. MD Functional bracing and rehabilitation of ankle fractures. CORR 1985 No 199, p 39

[23]. Duckworth T. A Prospective trial comparing operative and manipulative treatment of ankle fractures. JBJS 1986 VOL 68 B, p 610

[24]. E L F B Raaymakers, Malunited ankle fractures JBJS 1990 vol 72 B, p 709

[25]. Earle-Rockwood and Greens fractures in adults, fourth edition 1996, p 2201

[26]. Eichenholtz, Complications of ankle fractures in diabetic patients. OCNA JAN 2001 VOL 32, No 1, p 113.

[27]. Eugene J Carrage. Et al. Early complications in the operative treatment of ankle fractures. Influence of delay before operation. JBJS 1991 vol-73 B, p 79.

[28]. Fletcher A Reynolds. MD, Over tightening of the ankle syndesmosis. Is it really possible. JBJS 2001 vol 83 A, no 4, p 489.

[29]. Fred F Behrens Complications of ankle fractures in diabetic patients. OCNA JAN 2001 VOL 32, No 1, p 113

[30]. Freiburg. Evaluation of ankle fractures, Non operative and Operative treatment CORR 1979 No 138 , p 111

[31]. G H Robert Albers, Distal tibiofibular synostosis after ankle fracture. 1996JBJS,vol 78 B, p 250.

[32]. George P Whitelaw. MD Functional bracing and rehabilitation of ankle fractures. CORR 1985 No 199 , p 39.

[33]. Gregory. Joy et al. Precise evaluation of the reduction of severe ankle fractures. JBJS 1974, vol 56 A, No 5, p 979.

[34]. Harold C Leeds. Et al. Instability of the distal tibiofibular syndesmosis after bimalleolar and trimalleolar fractures. JBJS 1984, vol $66 \mathrm{~A}, \mathrm{p} 490$. 